\title{
Influence of mothers' characteristics on their perceptions and use of the growth chart
}

N. Al-Nahedh ${ }^{1}$ and E.A. Bamgboye ${ }^{1}$

$$
\begin{aligned}
& \text { تأثير طِباع الأمهات على استخدام لوحات النمو وتفهمها }
\end{aligned}
$$

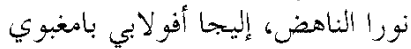

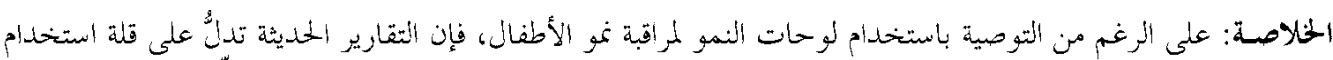

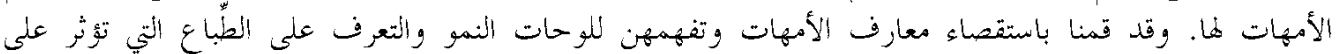

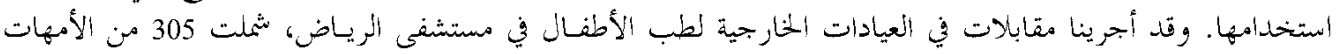

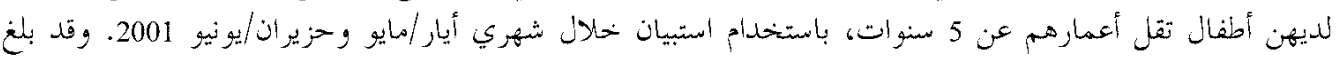

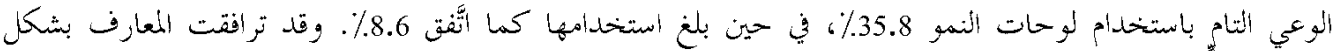

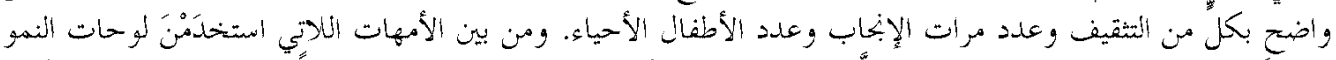

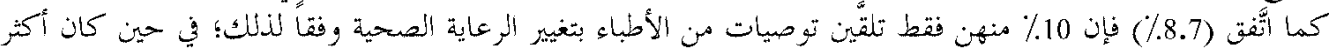

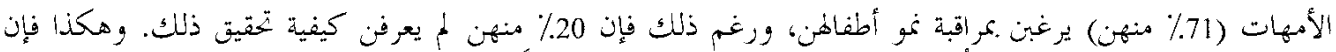

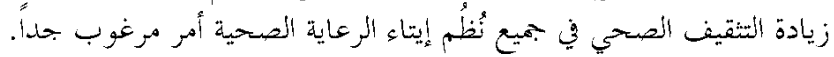

ABSTRACT Although growth charts are recommended for monitoring children, recent reports indicate poor use by mothers. We investigated maternal knowledge and perceptions of growth charts and identified characteristics affecting use. At outpatient paediatric clinics of a Riyadh hospital, 305 mothers with children under age 5 were interviewed by questionnaire during May-June 2001. Overall awareness of growth charts was $35.8 \%$ and ever-use was $8.6 \%$. Education, parity and number of living children were significantly associated with knowledge. Among mothers who ever used growth charts $(8.7 \%)$, only $10 \%$ reported doctors recommended changes in health care because of them. Overall, $71 \%$ wanted to monitor their child's growth, but $20 \%$ did not know how. Increased health education in all health care delivery systems is needed.

\begin{abstract}
Influence des caractéristiques des mères sur leurs perceptions et leur utilisation de la courbe de croissance

RESUME Bien que les courbes de croissance soient recommandées pour la surveillance des enfants, des rapports récents indiquent qu'elles sont peu utilisées par les mères. Nous avons examiné les connaissances des mères et leurs perceptions concernant les courbes de croissance et avons identifié les caractéristiques qui affectent l'utilisation. Aux consultations externes de pédiatrie d'un hôpital de Riyad, 305 mères ayant des enfants âgés de moins de 5 ans ont été interrogées par questionnaire durant mai et juin 2001. La connaissance globale des courbes de croissance était de $35,8 \%$, et $8,6 \%$ des mères les avaient déjà utilisées. L'instruction, la parité et le nombre d'enfants vivants étaient significativement associés avec les connaissances. Parmi les mères qui avaient déjà utilisé les courbes de croissance (8,7 \%), $10 \%$ seulement avaient signalé au médecin les changements introduits dans les soins de santé de ce fait. Globalement, $71 \%$ souhaitaient surveiller la croissance de leur enfant, mais $20 \%$ ne savaient pas comment faire. II est nécessaire de renforcer l'éducation sanitaire dans tous les systèmes de soins de santé.
\end{abstract}

${ }^{1}$ Department of Family and Community Medicine, College of Medicine, King Saud University, Riyadh, Saudi Arabia.

Received: 21/03/02; accepted: 28/01/03

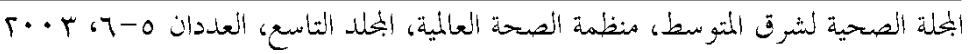




\section{Introduction}

Adverse changes in anthropometric measurements are indicators of childhood morbidity. Reference growth charts have therefore been assembled and the World Health Organization has recommended their use for the close monitoring of children's growth [1,2]. Studies of childhood growth have revealed that early detection of faltering growth is valuable as it facilitates quick intervention by mothers and doctors through better health care and appropriate nutritional changes [2].

The availability of this tool does not automatically translate to its use. Knowledge of its meaning and usefulness and its acceptance by the mothers who are directly in charge of childcare is necessary. Wide use of the growth chart suggests that mothers accept full responsibility for their children's care [3].

Many specific factors could be determinants of growth chart use. In Nigeria, for example, maternal age, education and parity were significantly influential factors in growth chart use [4].

Saudi Arabian health authorities are aware of the benefits of the successful implementation of a growth-monitoring programme. Accordingly, this concept was introduced in all primary health care (PHC) centres in the country in the last 10 years. Each child has a health booklet that is kept with the mother and a growth chart kept in the family's health folder in the PHC centre [5]. Recent reports, however, have indicated very poor use of the growth charts. The reasons for this are not fully understood and so remain a subject of interest to all maternal and child health workers [6].

Against this background our study was carried out with the main objectives of determining the level of knowledge and the perceptions of mothers about the growth charts and identifying maternal characteristics affecting use.

\section{Methods}

The study took place in the paediatric outpatient clinics of a teaching hospital in Riyadh, Saudi Arabia. For 6 weeks (May-June 2001) a structured questionnaire was completed for every third mother attending these clinics if her youngest child was aged less than 5 years. The items of information in the questionnaire included demographic characteristics of the mother, fertility history, anthropometric characteristics of the index child under 5 years, knowledge and awareness of growth charts, use of growth charts by mothers and doctors, effects of the use of growth charts on child care and the frequency of the child's admission to hospital. The questionnaire was pre-coded and trained research assistants conducted interviews with the mothers and recorded the information. Clarification of the term 'growth chart' was provided for those who needed it as 'child growth tables' (as they are called in Arabic) in which a doctor records a child's weight at each visit to see if the child is growing as he or she should.

Data was analysed with SPSS version 10 to produce frequency distributions of all variables. Descriptive statistics were used for qualitative and quantitative variables. Mothers' characteristics were cross-tabulated with maternal knowledge and perception of growth charts. Chi-squared test was used to investigate the significance of associations between any 2 categorical variables.

\section{Results}

Data collection was completed for 305 mothers during the study period. Table 1

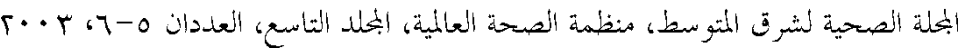


Table 1 Mothers' awareness, ever-use and perception of the usefulness of the growth chart by their demographic characteristics

\begin{tabular}{|c|c|c|c|c|}
\hline $\begin{array}{l}\text { Maternal } \\
\text { characteristics }\end{array}$ & $\begin{array}{l}\text { No. of } \\
\text { women }\end{array}$ & $\begin{array}{c}\text { Awareness } \\
\text { (\%) }\end{array}$ & $\begin{array}{l}\text { Growth chart } \\
\text { Ever-use at } \\
\text { home (\%) }\end{array}$ & $\begin{array}{l}\text { Perception of } \\
\text { usefulness (\%) }\end{array}$ \\
\hline \multicolumn{5}{|l|}{ Age (years) } \\
\hline $15-19$ & 3 & 0.0 & 0.0 & 100.0 \\
\hline $20-24$ & 22 & 27.3 & 17.4 & 90.9 \\
\hline $25-29$ & 73 & 34.2 & 5.5 & 88.7 \\
\hline $30-34$ & 89 & 36.0 & 5.5 & 92.0 \\
\hline $35-39$ & 66 & 42.4 & 15.2 & 85.1 \\
\hline $40-44$ & 45 & 35.6 & 6.7 & 88.9 \\
\hline Total & 298 & 35.9 & 8.7 & 89.2 \\
\hline$P$-value & & 0.593 & 0.138 & 0.805 \\
\hline \multicolumn{5}{|l|}{ Education $^{a}$} \\
\hline Illiterate & 35 & 11.4 & 11.4 & 77.1 \\
\hline Read and write & 16 & 25.0 & 12.5 & 75.0 \\
\hline Primary school & 45 & 20.0 & 4.4 & 95.6 \\
\hline Secondary & 121 & 41.3 & 7.4 & 90.9 \\
\hline University & 82 & 48.8 & 11.0 & 91.5 \\
\hline Total & 299 & 35.8 & 8.7 & 89.2 \\
\hline$P$-value & & 0.0001 & 0.639 & 0.024 \\
\hline \multicolumn{5}{|l|}{ Occupation } \\
\hline Full-time & 23 & 56.5 & 4.3 & 91.3 \\
\hline Part-time & 43 & 44.2 & 14.0 & 91.3 \\
\hline Homemaker & 230 & 32.6 & 7.8 & 89.1 \\
\hline Total & 296 & 36.1 & 8.4 & 89.2 \\
\hline$P$-value & & 0.037 & 0.307 & 0.911 \\
\hline \multicolumn{5}{|l|}{ Parity } \\
\hline 1 & 50 & 28.0 & 4.0 & 88.5 \\
\hline $2-4$ & 120 & 44.2 & 8.3 & 93.3 \\
\hline $5-8$ & 96 & 33.3 & 12.5 & 84.4 \\
\hline $9+$ & 29 & 20.7 & 3.4 & 89.7 \\
\hline Total & 295 & 35.6 & 8.5 & 89.2 \\
\hline$P$-value & & 0.043 & 0.216 & 0.181 \\
\hline \multicolumn{5}{|l|}{$\begin{array}{l}\text { Number of living } \\
\text { children }\end{array}$} \\
\hline 1 & 55 & 27.3 & 5.5 & 88.7 \\
\hline $2-4$ & 119 & 44.5 & 7.6 & 93.3 \\
\hline $5-8$ & 98 & 33.7 & 12.2 & 84.7 \\
\hline $9+$ & 25 & 16.0 & 4.0 & 88.0 \\
\hline Total & 297 & 35.4 & 8.4 & 89.2 \\
\hline$P$-value & & 0.017 & 0.319 & 0.216 \\
\hline
\end{tabular}

${ }^{a}$ Highest level completed. 
shows the demographic characteristics of these mothers by their awareness of the growth chart, their ever-use of it in the home and their perceptions of its usefulness. Table 1 shows that the response rate to the question on knowledge, or awareness, of the growth chart was $98 \%$ (7 mothers did not respond). Overall awareness and ever-use of the monitoring growth chart were generally poor $35.8 \%$, 95\% CI: $30.4 \%-41.2 \%$ and $8.6 \%$, 95\% CI: $5.4 \%-11.8 \%$ respectively).

Many mothers (76.5\%) were aged between 25 and 39 years. Only $1.0 \%$ of mothers were younger than 20 years and $15.1 \%$ were older than 39 years. There were no statistically significant differences by age in the proportion of mothers with awareness, ever-use or good perceptions of the growth chart $(P>0.1)$.

Maternal education was statistically significant in association with awareness of the growth chart $(P<0.05)$. The proportion of mothers who were aware of the growth chart increased from $11.4 \%$ for illiterate mothers to $48.8 \%$ for mothers with more than secondary education.

Overall, the majority of mothers (89.2\%) perceived the growth chart as a useful monitoring tool for child health and development. This perception increased significantly from $77.1 \%$ of illiterate mothers to more than $90 \%$ of those with at least primary education.

Only $8.7 \%$ reported ever using the growth chart and there was no statistically significant age differential. The trend of use was inconsistent across age groups; however, those aged between 35 and 39 years were more likely to use the growth chart than other mothers.

The mother's occupation was also statistically significant in association with the mother's knowledge of the growth chart $(P<0.05$; Table 1$)$. Mothers engaged in full-time work were more aware of the growth chart than those with part-time jobs or those who were not employed outside the home $(56.5 \%, 44.2 \%$ and $32.6 \%$ respectively).

We examined total parity and total number of living children as maternal variables related to growth chart use and perceptions. Both variables were statistically significant in association with mother's knowledge of the growth chart $(P<0.05$; Table 1). Multiparous women were less aware of the growth chart than were women with parity 2-4. A greater proportion of women with 2-4 living children were also more aware of the growth chart than women with either more or fewer children. Although only 25 women had 9 or more living children, these women were least likely to know of or to have ever used the growth chart. Neither parity nor number of living children was statistically significant in association with mothers' use of growth chart or perception of its usefulness.

The child's age, sex and recent illness were not statistically significant in association with the mother's awareness, ever-use or perception of the usefulness of the growth chart (Table 2). Mother's awareness and perception of the usefulness of the growth chart were not statistically associated with child's birth weight. However, a greater proportion of mothers of high-birth-weight babies reported use of the growth chart than did their counterparts with smaller birth-weight babies $(P<$ 0.05 ). A significantly greater proportion of mothers of children who were not recently hospitalized were aware of the growth chart $(39.5 \%$ versus $14.6 \%, P<0.01)$.

Almost $80 \%$ of mothers reported doctor's use of the growth chart at least occasionally. In almost $67 \%$ of these cases, doctors did not interfere with nutrition or health care of the child based upon the information recorded in the growth chart. Among mothers who ever used the growth

المحلة الصحية لشرق المتوسط، منظمة الصحة العالمية، البخلد الثاسع، العلدان 0-7، ب +. 
Table 2 Mother's awareness, ever-use and perception of the usefulness of the growth chart by her youngest child's characteristics

\begin{tabular}{|c|c|c|c|c|}
\hline $\begin{array}{l}\text { Youngest child's } \\
\text { characteristics }\end{array}$ & No. of children & Awareness (\%) & $\begin{array}{l}\text { Growth chart } \\
\text { Ever-use } \\
\text { at home (\%) }\end{array}$ & $\begin{array}{l}\text { Perception of } \\
\text { usefulness (\%) }\end{array}$ \\
\hline \multicolumn{5}{|l|}{ Age (months) } \\
\hline $1-6$ & 98 & 35.7 & 9.2 & 89.8 \\
\hline $7-12$ & 78 & 44.9 & 10.3 & 94.9 \\
\hline $13-24$ & 73 & 31.5 & 9.6 & 83.6 \\
\hline $25-36$ & 13 & 38.5 & 7.7 & 92.3 \\
\hline $37-60$ & 7 & 42.9 & 0.0 & 71.4 \\
\hline Total & 269 & 37.5 & 9.3 & 89.2 \\
\hline$P$-value & & 0.533 & 0.921 & 0.49 \\
\hline \multicolumn{5}{|l|}{ Sex } \\
\hline Male & 158 & 34.2 & 8.9 & 88.6 \\
\hline Female & 138 & 37.9 & 8.7 & 89.9 \\
\hline Total & 296 & 35.8 & 8.8 & 89.2 \\
\hline$P$-value & & 0.43 & 0.94 & 0.730 \\
\hline \multicolumn{5}{|l|}{ Birth weight (kg) } \\
\hline$<2.5^{\mathrm{a}}$ & 54 & 24.1 & 7.4 & 83.3 \\
\hline $2.5-3.9$ & 224 & 38.4 & 7.1 & 90.1 \\
\hline $4.0+$ & 20 & 45.0 & 25.0 & 90.0 \\
\hline Total & 298 & 36.2 & 8.4 & 89.6 \\
\hline$P$-value & & 0.101 & 0.021 & 0.223 \\
\hline \multicolumn{5}{|l|}{ Recent illness } \\
\hline Yes & 98 & 31.6 & 12.2 & 86.7 \\
\hline No & 199 & 38.2 & 7.0 & 90.9 \\
\hline Total & 297 & 36.0 & 8.7 & 89.6 \\
\hline$P$-value & & 0.268 & 0.125 & 0.263 \\
\hline \multicolumn{5}{|c|}{ Recent hospitalization } \\
\hline Yes & 41 & 14.6 & 14.6 & 85.4 \\
\hline No & 256 & 39.5 & 7.8 & 89.8 \\
\hline Total & 297 & 36.0 & 8.7 & 89.2 \\
\hline$P$-value & & 0.002 & 0.144 & 0.406 \\
\hline
\end{tabular}

a Low birth weight.

chart at home (8.7\%), only $10 \%$ reported the doctor had recommended a change in health care based upon the reading of the growth chart. Overall $71 \%$ of mothers professed enthusiasm to take an active role in monitoring their child's growth with a growth chart, but $20 \%$ did not know how to do this.

\section{Discussion}

Overall knowledge of the growth chart as indicated by the level of awareness in our study was $35.8 \%$, which is very low in comparison with nearly $80 \%$ in Al-Khobar, Saudi Arabia [6], and 54\% in Ilorin, Nigeria

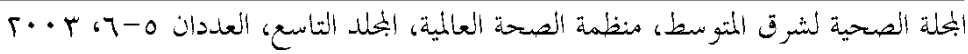


[4]. This suggests a need for related health education in PHC settings, maternity centres and other health care delivery systems in the country. Knowledge of the growth chart would encourage mothers to use it at home and to be completely in charge of monitoring their children's growth [7].

The significant influence of the mother's education, job, parity and number of living children on her awareness of the growth chart is consistent with a previous report [4]. This may not be surprising as education buys awareness and the more educated a mother is, the more likely she is to appreciate the need to monitor her children's growth. The educated mother understands the consequences of any faltering of growth in her children. Such knowledge also makes the mother an active participant in decisions regarding the diet, feeding and child health practices needed to achieve normal growth.

Because more than $70 \%$ of mothers expressed a desire to record their child's anthropometric measurements at home, an effort should be made to teach and actively involve mothers in this activity. Each PHC centre in the country should have a qualified health educator and the health educa- tion content of the growth chart should be reviewed regularly to ensure the mother's understanding [8].

The frequency of cases in which doctors made changes in childcare based upon the mother's report of her use of the growth chart was low. In some of these cases, the doctors may have chosen to wait and re-examine the child before making changes in care. That mothers were able to read the growth chart and sound a note of warning about the child's poor growth, however, is an achievement towards the objective of the growth monitoring system.

Maternal age influenced awareness and perception of the growth chart in previous studies but was not significant in this study. It was, however, indirectly involved in the effect of education, parity and number of living children. Future studies are expected to throw more light on the awareness and the perception of mothers about the use of the growth chart and whether or not proper use and modification of health care actually occurs based upon readings of it.

Physician compliance and its impact on mothers should not be underestimated and therefore should be encouraged.

\section{References}

1. A growth chart for international use in maternal and child health care: Guidelines for primary health care personnel. Geneva, World Health Organization, 1978.

2. Jelliffe DB, Jelliffe EFP. Using growth charts to improve nutrition. Geneva, World Health Organization, 1985.

3. Grant K, Stone T. Maternal comprehension of a home-based growth chart and its effect on growth. Journal of tropical pediatrics, 1986, 32:253-7.
4. Fagbule DO, Olaosebikan A, Parakoyi DB. Community awareness and utilization of growth charts in a semi-urban $\mathrm{Ni}$ gerian community. East African medical journal, 1990, 67:69-74.

5. Sebai ZA. Primary health care in the district of Al-Asiah. In: Sebai ZA, ed. Community health in Saudi Arabia. Jeddah, Tihama Publications, 1984:71-6.

6. Rasheed $P$ et al. The growth chart-its use and perception among mothers visiting primary health care centres of $\mathrm{Al}$ -

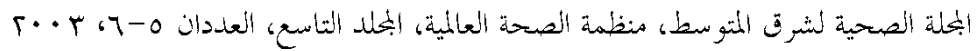


Khobar, Saudi Arabia. Saudi medical journal, 1996, 17(2):195-204.

7. Brown R, Morley D. A controlled trial weighing with the Direct Recording Scale by mothers in a village based growth monitoring programme in Ghana.
Journal of tropical pediatrics, 1993, 39: 55-8.

8. Kumar V, Datta N. Home-based mothers' health records. World health forum, 1988, 9:107-10.

\section{WHO Global Database on Child Growth and Malnutrition}

The Global Database on Child Growth and Malnutrition is a dynamic catalogue of representative population-based nutrition data that are collected and assessed in a standardized manner. Its primary focus is undernutrition among infants and children under 5 years of age computed on the basis of weight-for-age (underweight), weight-forheight (wasting), and height-for-age (stunting), although information on the prevalence of overweight in children is also included. The database currently covers about 510 million children, or $95 \%$ of the total population of under-5-year-olds. These figures reflect only nationally representative surveys. Additional data are available for some countries from surveys conducted at regional, provincial, state, district, or local levels. The database also provides country trend analyses from 1980 onwards.

The Global Database on Child Growth and Malnutrition provides decision-makers and health workers alike with baseline information. This information takes the forms of maps, tables, graphs, and data in electronic formats, which are needed to plan, implement, and monitor and evaluate intervention programmes aimed at promoting healthy child growth, nutrition, and development. The database is available free on line at: http://www.who.int/nutgrowthdb/ 